CULVER, K. C.; CUPPLES, Brian. Why witholding treatment is not assisted suicide. Health Law in Canada, v. 20, n. 2, p.12-16, nov.,1999.

ESTADO DE SÃO PAULO. Lei n. 10.241. Diário Oficial do Estado de São Paulo em 17 de março de 1999.

EVANGELIUM VITAE. Carta encíclica de João Paulo // sobre o valor e a inviolabilidade da vida humana. 2. ed. São Paulo: Paulinas, 1995.

FRAGA, Márcio André Keppler. A atipicidade penal da ortotanásia. Revista da Ajuris, v. 26, n. 78, p. 163-168, jun. 2000.

GAFO FERNÁNDEZ, Javier. 10 palavras-chaves em bioética. Trad. Maria Luisa Garcia Prada. São Paulo: Paulinas, 2000.

GASPARINI, Diógenes. Direito administrativo. 4. ed. São Paulo: Saraiva, 1995.

GOSTIN, Lawrence. Drawing a line between killing and letting die. The Journal of Law, Medicine \& Ethics, v. 21, n. 1, p. 94-101, spring 1993.

HOSSNE, William Saad. Entre a ética, a fé e a ciência. (Entrevista) Época, São Paulo: 27 ago. 2001, p. 54-56.

PITHAN, Lívia Haygert. A dignidade humana como fundamento jurídico das "ordens de não-ressuscitação". Porto Alegre: EDIPUCRS, 2004.

SANTOS, Maria Celeste Cordeiro Leite dos. Contornos atuais da eutanásia e da ortotanásia: bioética e biodireito. A necessidade do controle social das técnicas médicas. Rev. da Fac. Direito USP, São Paulo, p. 265-278, 1999.

ZAFFARONI, Eugênio Raúl; BATISTA, Nilo. Direito penal brasileiro. Rio de Janeiro: Revan, 2003.

ZAFFARONI, Eugenio Raúl; PIERANGELI, José Henrique. Manual de direito penal brasileiro: Parte Geral. 5. ed. São Paulo: Ed. Revista dos Tribunais, 2004.

\title{
Morte Digna: Direito Natural do Ser Humano
}

DIGNITY IN DEATH: NATURAL RIGHT OF HUMAN BEING

Fernando Aith ${ }^{(\star)}$

Em 28 de novembro de 2006 o Conselho Federal de Medicina (CFM) tomou uma decisão polêmica que representa um importante marco regula-

(*) Doutor em Saúde Pública pela Faculdade de Saúde Pública da Univerisdade de São Paulo (FSP. USP), especialista em Direito Médico e da Saúde pela Universidade de Paris 8, mestre em Filosofia e Teoria Geral do Direito pela Faculdade de Direito da USP, pesquisador do Centro de Estudos e Pesquisas de Direito Sanitário e professor de Redação e Estratégia Legislativa da Escola de Direito da Fundação Getúlio Vargas - EDESP-FGV/SP. E-mail: <feaith@uol.com.br>. 
tório no Brasil. Trata-se da Resolução CFM n. 1.805/06 (1) que dispõe sobre o tratamento médico que pode ser dado a um doente em fase terminal, portador de enfermidade grave e incurável. llumina-se, assim, um tema que é pouco confortável para os seres humanos, mas que se configura como destino inelutável de todos.

A Resolução do CFM possui, desde já, a função de estimular o necessário debate que a sociedade brasileira deve fazer para decidir, democraticamente, quais as possiveis formas de se tratar um ser humano que sofre intoleráveis dores físicas, psicológicas e morais decorrentes de uma enfermidade terminal e incurável. Em última análise, trata-se de discutir a possibilidade ou não de se praticar a eutanásia no Brasil.

$\mathrm{Na}$ definição de Houaiss, a eutanásia é o "ato de proporcionar morte sem sofrimento a um doente atingido por afecção incurável que produz dores intoleráveis"(2). A grande característica da eutanásia médica é a misericórdia, o humanismo de evitar sofrimentos inúteis e intoleráveis por parte de um ser humano que tem a sua morte inevitavelmente próxima. Tratase de preservar a dignidade humana também nesse difícil momento, que é a hora de se despedir desta vida.

O tema da eutanásia suscita discussões jurídicas, morais, religiosas, éticas, políticas e ideológicas. A análise a ser realizada neste momento focará essencialmente as questões jurídicas inerentes ao tema, à luz do ordenamento jurídico brasileiro.

Inicialmente, vale verificar o teor da Resolução CFM n. 1.805/06 e as limitações de sua aplicação.

\section{I - SIGNIFICADO E LIMITES DA RESOLUÇÃO CFM N. 1805/06}

Para analisar a Resolução do CFM em seus múltiplos aspectos, convém verificar, preliminarmente: a) o poder de regulação do CFM; e b) o significado do texto expresso na Resolução n. 1.805/06.

\section{A - O poder de regulação do Conselho Federal de Medicina}

O Conselho Federal e os Conselhos Regionais de Medicina foram criados pela Lei n. 3.268, de 30 de setembro de 1957. Desde então, os Conse-

(1) Resolução CFM n. 1805/06, publicada no Diário Oficial da União no dia 28 de novembro de 2006, Seção I, pág. 169.

(2) Dicionário Houaiss. Etimologicamente, euthanasia quer dizer 'morte sem sofrimento' (pelo lat. euthanasia 'id.'; ver eu-e tanat(o)-; f.hist. 1836 euthanasia). 
Ihos Federal e Regionais de Medicina passaram a ser os órgãos supervisores da ética profissional em toda a República e, ao mesmo tempo, julgadores e disciplinadores da classe médica, cabendo-lhes zelar e trabalhar por todos os meios ao seu alcance, pelo perfeito desempenho ético da Medicina e pelo prestígio e bom conceito da profissão e dos que a exerçam legalmente.

O Conselho Federal possui as suas atribuições definidas no art. $5^{\circ}$ da citada Lei, dentre as quais se destacam as de organizar o seu regimento interno; aprovar os regimentos internos organizados pelos Conselhos Regionais; votar e alterar o Código de Deontologia Médica, ouvidos os Conselhos Regionais; propor ao Governo Federal a emenda ou alteração do Regulamento de sua lei constitutiva; expedir as instruções necessárias ao bom funcionamento dos Conselhos Regionais.

Como se pode verificar, a Lei confere ao CFM uma série de funções normativas, válidas para os profissionais sujeitos à sua jurisdição. Sempre necessário lembrar que as funções normativas infralegais dos Conselhos de Classe são limitadas pela Constituição e pelas leis e não podem contrariar, sob nenhuma condição, os dispositivos legais existentes no ordenamento jurídico.

Das normas baixadas pelo CFM destacam-se o seu Estatuto (Resolução CFM n. 1.541, de 18 de dezembro de 1998) e o Código de Ética Médica, (Resolução CFM n. 1.246, de 8 de janeiro de 1988), a ser seguido pelos profissionais de Medicina no Brasil. De acordo com o art. $2^{\circ}$ do Código de Ética Médica, "o alvo de toda a atenção do médico é a saúde do ser humano, em benefício da qual deverá agir com o máximo de zelo e o melhor de sua capacidade profissional". Deve-se aplicar para o termo saúde, empregado pelo Código de Ética Médica, o conceito da Organização Mundial de Saúde (OMS), segundo o qual, "saúde é o estado de completo bem-estar físico, mental e social, e não somente a ausência de doenças ou enfermidades"(3).

Em resumo, o CFM é órgão regulador da atividade de medicina no Brasil, possuindo competências normativas próprias. As normas do CFM, exaradas por meio de Resoluções, são hierarquicamente inferiores às leis e à Constituição Federal, vale dizer, tais normas devem observar, obrigatoriamente, os limites impostos pela ordem jurídica instaurada no país.

\section{B - O significado do texto expresso na Resolução CFM n. 1.805/06}

A Resolução CFM n. 1.805/06 dispõe, em seu art. 1, que "é permitido ao médico limitar ou suspender procedimentos e tratamentos que prolonguem a vida do doente em fase terminal, de enfermidade grave e incurável, respeitada a vontade da pessoa ou de seu representante legal". O dispositivo

(3) Preâmbulo da Constituição da Organização Mundial de Saúde. 
define, nestes termos, os limites éticos de atuação do médico em benefício do bem-estar dos pacientes portadores de enfermidades graves e incuráveis e que estejam em fase terminal de vida.

Para analisar o conteúdo da Resolução, portanto, necessário se faz a delimitação de alguns outros conceitos, relacionados com a eutanásia. Etimologicamente, eutanásia vem do grego "eu", que significa boa, e "thanatos", que significa morte. Eutanásia significa, portanto, a boa morte, a morte em condições dignas. Existe uma distinção entre eutanásia ativa, eutanásia passiva (ortotanásia), eutanásia indireta e o auxilio ao suicídio. Vale tecer breves considerações a respeito do assunto, por serem fundamentais para a compreensão do teor da Resolução CFM n. 1.805/06 e, em última análise, para a verificação de sua constitucionalidade e legalidade.

A eutanásia ativa ocorre quando o tratamento terapêutico é administrado com o objetivo explícito de abreviar a vida do paciente. A eutanásia ativa envolve um conjunto de ações (que podem ser estabelecidas por meio de um tratamento terapêutico) que tem por objetivo pôr termo à vida. $\mathrm{Na}$ eutanásia ativa é preciso uma ação de um agente externo para que a morte se efetive.

A eutanásia passiva ou ortotanásia ocorre quando a doença por si mesma conduz à morte inevitável do paciente (neoplasias, por exemplo). A ortotanásia implica na suspensão ou limitação do tratamento terapêutico em razão das condições de saúde do paciente e dos efeitos colaterais que o tratamento produz. A eutanásia passiva tem como resultado permitir que a doença evolua até que a mesma provoque a morte natural da pessoa. Como visto, tal procedimento tem como conseqüência a abreviação da vida do paciente, em decorrência do abandono de um tratamento terapêutico que poderia prolongá-la. Mas este procedimento somente será realizado quando o sofrimento causado pelo tratamento for igual ou ainda pior do que o sofrimento da própria doença. Por essa razão, a eutanásia passiva implica, ainda, no esforço para que a ocorrência da morte natural seja o mais confortável possível. São oferecidos ao enfermo os cuidados paliativos necessários para minimizar ou eliminar os sofrimentos físicos e mentais causados pela evolução da doença. A eutanásia passiva contribui para que a morte natural decorrente de uma doença terminal se dê sem sofrimento.

A eutanásia indireta, por sua vez, é a administração de um medicamento ou produto que possui, dentre seus efeitos colaterais, a faculdade de abreviar a morte do doente (como, por exemplo, o uso da morfina, que diminui a dor do paciente, mas que acelera sua morte).

Parece claro, portanto, que a Resolução n. 1.805/06 autoriza o médico a realizar a ortotanásia ou eutanásia passiva, ou seja, a limitar ou suspender procedimentos e tratamentos que prolonguem a vida do doente em fase terminal, de enfermidade grave e incurável. Assim, o sentido dado por esta 
resolução é o de permitir aos médicos a prática de uma Medicina voltada a oferecer, quando necessário, uma boa morte.

Também importante a distinção entre a eutanásia voluntária, involuntária e por consentimento de representante legal. A eutanásia voluntária ocorre quando o paciente, em plenas capacidades psíquicas e mentais, solicita auxílio do médico para que este adote procedimentos que o encaminhem para uma boa morte, ou morte digna. A eutanásia involuntária acontece quando o paciente ainda possui consciência e a eutanásia é realizada contra a sua vontade (caracterizada, no Brasil, como homicídio). Finalmente, temos aquela realizada por consentimento de representante legal, situação na qual o doente não tem mais consciência, cabendo ao representante legal decidir pela realização da eutanásia ou não. De preferência, tal decisão deve ter como base as vontades que o paciente tenha demonstrado quando ainda era consciente (nesse caso se caracterizaria como uma eutanásia voluntária). O problema ocorre quando não se conhece a vontade do paciente que já se encontra inconsciente.

Feitas essas distinções, fica claro que a resolução ora debatida somente autoriza o médico a realizar a eutanásia passiva voluntária ou por consentimento de representante legal, sendo vedada terminantemente a realização de eutanásia passiva involuntária ou de eutanásia ativa. Isso porque 0 art. $1^{\circ}$ diz expressamente que a limitação ou suspensão do tratamento deve ser feita respeitada a vontade da pessoa (voluntária) ou de seu representante legal (não-voluntária).

A resolução também é bastante incisiva ao determinar que o doente continuará a receber todos os cuidados necessários para aliviar os sintomas que levam ao sofrimento, assegurada a assistência integral, o conforto físico, psíquico e espiritual, inclusive assegurando-lhe o direito de alta hospitalar (art. $\left.2^{\circ}\right)$.

Como se pode ver, trata-se de uma resolução humanista, que visa evitar o sofrimento inútil de um ser humano, quando este não tiver mais possibilidades de se manter vivo senão às custas de um injustificável e penoso tratamento que o expõe a sofrimento e que pode se assemelhar a um tratamento desumano. Visa-se, assim, à preservação da dignidade humana no fim da vida.

Embora Constitucional, é importante notar que o médico que adotar tal prática poderá sofrer ação penal por crime contra a vida. Há quem entenda que todo e qualquer tipo de eutanásia, inclusive a passiva, representa crime de homicídio culposo ou doloso, a depender do caso. As dificuldades de diferenciar o excesso terapêutico e a terapêutica que pode salvar complicam ainda mais a questão. Daí a necessidade premente da sociedade brasileira se movimentar para decidir, por Lei aprovada pelo Congresso Nacional, qual o entendimento do Brasil sobre o fim da vida de um ser humano. 
Até que isso aconteça, a prática médica e a jurisprudência vão dar 0 tom dessa discussão no Brasil.

\section{II - O PRINCÍPIO DA DIGNIDADE HUMANA E O DIREITO DO PACIENTE A UMA MORTE DIGNA}

\section{A - O valor jurídico do princípio de proteção da dignidade da pessoa humana}

Inicialmente, convém ressaltar que a dignidade humana é um princípio de valor constitucional, reconhecido expressamente pela Constituição Federal de 1988. Assim, logo no inciso III do art. $1^{\circ}$ da Constituição temos a menção ao princípio da dignidade da pessoa humana: "A República Federativa do Brasil, formada pela união indissolúvel dos Estados e Municípios e do Distrito Federal, constitui-se em Estado Democrático de Direito e tem como fundamentos: (...) III - a dignidade da pessoa humana".

A proteção da dignidade da pessoa humana representa, assim, um dos fundamentos do Estado brasileiro. Tal condição nos permite qualificá-lo como um princípio matricial do Direito, uma vez que de seu conteúdo derivam outros princípios protetores dos direitos humanos fundamentais ${ }^{(4)}$. Para além da afirmação do valor constitucional do principio de proteção da dignidade da pessoa humana, ainda restam muitas dúvidas sobre a sua aplicação concreta perante os tribunais de todo o mundo.

A aplicação jurídica do princípio de proteção da dignidade humana mostra-se ilimitada, sobretudo quando tratamos de saúde. Na França, o poder judiciário declarou que a obrigação do médico de informar ao seu paciente o seu quadro médico preciso tem como fundamento este princípio ${ }^{(5)}$. No Brasil, a dignidade da pessoa humana tem sido usada constantemente como fundamento de Habeas Corpus contra arbitrariedades de autoridades estatais. Também há decisões do Supremo Tribunal Federal que associam a prática da tortura e do rascismo a práticas que atentam contra esta dignidade ${ }^{(6)}$. Os exemplos de amplitude do significado deste princípio são vários. A própria Constituição o utiliza como fundamento do Estado brasileiro (art. 1ํㅡ,

(4) MATHIEU, B. Pour la reconnaissance d' un principe matriciel, D. 1995, chron. p. 211.

(5) Civ. 1e, 9 octobre 2001, Bull. civ. I, n. 249; B. Pitcho, De l'indignité médicale face au temps, JCP 2002, éd. E, suppl. Cah. dr. entr. 2002/1, p. 27; D. 2001, p. 3470, rapp. P. Sargos, note D. Thouvenin; Gaz. Pal. 17-18 octobre 2001, p. 19; Gaz. Pal. 2001, juris. p. 1818, note J. Guigue; JCP 2002, II, 10045, note O. Cachard; C. Clément, Le médecin, son devoir d'information et le principe constitutionnel de sauvegarde de la dignité humaine, Petites affiches 6 décembre 2001, p. 15; F. Chabas, L'obligation d'information à laquelle un médecin s'est soustrait doit être appréciée en fonction de la jurisprudence actuelle. RJPF janvier 2002, p. 21; RTD civ. 2002, p. 176, obs. R. Libchaber; Add. CA Paris, 29 novembre 2001, D. 2003, somm. p. 661, obs. C. Pomart.

(6) HC n. 70.389/SP - São Paulo; Ministro Relator Sidney Sanches, julgamento 23 de junho de 1994. 
III), como fundamento da necessidade de planejamento familiar (art. 226, $\S 7^{\circ}$ ), como um direito da criança, do adolescente e do idosos (art. 227, caput e art. 230, caput).

O princípio da dignidade humana adquire um valor jurídico incerto na medida que constatamos a sua múltipla função e, sobretudo, na medida que nos apercebemos de que se trata de um princípio jurídico voltado à proteção de todos, inclusive àqueles que não possuem consciência de sua própria dignidade (como as pessoas idosas que possuem esclerose múltipla, os portadores do mal de Alzheimer, as pessoas em coma, alguns deficientes mentais etc.).

A sociedade precisa, assim, para respeitar este princípio em relação às pessoas que não têm mais noção de sua própria dignidade, fazer valer uma noção geral de dignidade, qual seja: a da dignidade humana. Assim, a dignidade do doente de Alzheimer será garantida, concretamente, pelos enfermeiros e familiares que o circundam, pelos médicos que o tratam; tais profissionais e pessoas devem ser dignos para com esse "ausente". Eles devem respeitá-lo e, também, respeitarem-se. Afinal, "pode uma pessoa que sotre do mal de Alzheimer em estágio avançado, quando toda a memória se perde, ter consciencia sobre o tratamento que as pessoas devem dar a ela ou sobre o tratamento que ela deve dar-se a si mesma? A dignidade dessa pessoa só poderá ser realmente estabelecida através da dignidade da pessoa que cuida dela"(7).

Embora seja um princípio de valor constitucional, o seu significado carece de precisão jurídica. Para dotar o princípio de proteção da dignidade humana de uma maior precisão jurídica, convém tentar compreender meIhor a sua relação com os direitos específicos que the dão concretude, assegurados por normas jurídicas diversas.

\section{B - O princípio da dignidade da pessoa humana como fundamento do di- reito à integridade física e mental do ser humano (CF e Lei n. 8.080/90)}

A Constituição Federal dedica alguns dispositivos para a proteção da integridade da pessoa humana. Logo no art. 5ㄴ, III, encontra-se o princípio jurídico básico de que "ninguém será submetido a tortura nem a tratamento desumano ou degradante"(8). Tal dispositivo abrange os tratamentos médi-

(7) CLEMENT, J.M. Les Grands Principes du Droit de La Santé. Ed. Études Hospitalières, p. 51.

(8) No Brasil, a proteção contra a tortura e tratamentos degradantes: Art. $4^{\circ}$, $b$, da Lei n. 4.898/1965 (abuso de autoridade); Art. 233 da Lei n. 8.096/1990 (Estatuto da Criança e do Adolescente); Arts. $2^{\circ}$ a $8^{\circ}$ da Lei n. 8.072/1990 (Crimes Hediondos); Lei n. 9.455/1997 (crimes de tortura); Lei n. 8.072/1990 (crimes hediondos); Decreto 40/1991 (Ratifica convenção contra tortura e outros tratamentos ou penas cruéis, desumanos ou degradantes); Art. $5^{\circ}$ do Decreto 678/1992 (Promulga a Convenção Americada sobre Direitos Humanos - Pacto de São José da Costa Rica). No que se refere à prática de tortura, 0 art. $5^{\circ}$, XLIII determina que a lei considerará tal crime inafiançável e insuscetível de graça ou anistia, assim como os crimes que vierem a ser considerados hediondos. 
cos e outras ações relacionados com a prática da medicina. À luz desse dispositivo a integridade física e mental do ser humano fica juridicamente protegida contra eventuais tratamentos médicos (proibição de choques para tratamento de doentes mentais, por exemplo), contra a realização de pesquisas científicas em cobaias humanas, contra a comercialização de órgãos humanos, entre outros procedimentos que podem ser caracterizados como tortura ou tratamentos desumanos ou degradantes.

A Lei n. 8.080/90 também tratou de fixar a proteção da integridade física e mental do ser humano definindo-a como um princípio do Sistema Único de Saúde, nos seguintes termos: "Art. $7^{\circ}$ As ações e serviços públicos de saúde e os serviços privados contratados ou conveniados que integram o Sistema Único de Saúde (SUS), são desenvolvidos de acordo com as diretrizes previstas no art. 198 da Constituição Federal, obedecendo ainda aos seguintes princípios: (...) III - preservação da autonomia das pessoas na defesa de sua integridade física e moral".

Sendo um princípio do SUS, a preservação da integridade física e moral do ser humano deve ser uma prioridade de todos os que, de alguma forma, desenvolvem as ações e serviços públicos de saúde no Brasil.

\section{C-A proteção da integridade física e mental da pessoa humana no Código de Ética Médica (CEM)}

O Código de Ética Médica (CEM) é um libelo à vida digna e apresenta diversos dispositivos voltados à proteção da integridade física e mental dos pacientes. Trata-se de um documento importante no âmbito do Direito Sanitário, sobretudo no que se refere ao principio da proteção da dignidade humana. Prevê o art. 6 do CEM que "o médico deve guardar absoluto respeito pela vida humana, atuando sempre em benefício do paciente. Jamais utilizará seus conhecimentos para gerar sofrimento físico ou moral, para o extermínio do ser humano, ou para permitir e acobertar tentativa contra sua dignidade e integridade".

A prática da Medicina, voltada ao tratamento de seres humanos, deve observar ditames éticos rígidos e, sobretudo, deve ser executada em estrita observância das limitações legais. Assim, compete ao médico indicar o procedimento adequado ao paciente, observadas as práticas reconhecidamente aceitas e respeitando as normas legais vigentes no País. Não pode o profissional de Medicina realizar, em seus pacientes, experiências irresponsáveis. Ele deve ater-se aos procedimentos e práticas reconhecidamente aceitas pelo meio e autorizadas pelas autoridades públicas competentes, sobretudo a Agência Nacional de Vigilância Sanitária (ANVISA). É proibido ao médico praticar ou indicar atos médicos desnecessários ou proibidos pela legislação do País (CEM, arts. 21 e 42).

O médico é o responsável pelos atos profissionais que pratica, devendo tomar todos os cuidados possíveis para evitar atos danosos ao paciente, 
em especial aqueles que possam ser caracterizados como imperícia, imprudência ou negligência (CEM, arts. 23 e 29).

O CEM consagrou ainda o principio do consentimento como corolário da prática da Medicina. É expressamente "vedado ao médico efetuar qualquer procedimento médico sem o esclarecimento e consentimento prévios do paciente ou de seu responsável legal, salvo iminente perigo de vida" (art. 46). O consentimento ao qual se refere o CEM é aquele livre e esclarecido do doente, não podendo o médico exercer sua autoridade de maneira a limitar o direito do paciente de decidir livremente sobre a sua pessoa ou seu bem-estar (art. 48) ${ }^{(9)}$. De fato, o doente encontra-se, invariavelmente, em situação de vulnerabilidade diante de um médico, sendo que esta é diretamente proporcional à gravidade da doença que o acomete e ao grau de instrução deste. Quanto mais leigo o paciente, e quanto mais grave a doença, maior será sua vulnerabilidade. O médico deve atuar com equilibrio e ter consciência que a decisão final sobre o tratamento será do paciente, pois é ele o mais apto a escolher a alternativa terapêutica que mais lhe convém.

Ainda com relação à proteção da integridade física e mental do paciente, é proibido ao médico participar da prática de tortura ou de outras formas de procedimento degradantes, desumanas ou cruéis, ser conivente com tais práticas ou não as denunciar quando delas tiver conhecimento, bem como fornecer meios, instrumentos, substâncias ou conhecimentos para a realiação de tais práticas (arts. 49 e 50). Em termos éticos, significa dizer que, em algumas situações, o tratamento médico a ser adotado no doente terminal é tão invasivo e violento que se configura como um tratamento desumano e degradante.

Pode-se ver que o Código de Etica Médica, que submete todos os profissionais médicos, estabelece diversas normas jurídicas voltadas expressamente a defender a integridade física e mental do paciente ${ }^{(10)}$ e proteger, assim, a dignidade da pessoa humana. A Resolução n. 1.805/06 apenas veio corroborar tal regra e dar-lhe maior concretude. Na medida em que a prorrogação injustificada de tratamentos médicos pode ter o duplo efeito de agravar o bem-estar físico ou mental do paciente e ao mesmo tempo mantêlo vivo, compete ao CFM, de fato e de direito, disciplinar os limites de tais ações. Sem dúvida seria mais adequado se o Congresso Nacional, por Lei, disciplinasse o tema. Mas, no vácuo legislativo, o órgão de classe dos profissionais médicos tem legitimidade e poder regulatório para, dentro dos princípios constitucionais, propor normas de procedimento ético com soluções concretas para situações vividas no dia-a-dia da prática do profissional de saúde.

(9) Sobre a obrigatoriedade do consentimento do paciente, o Código Civil regula o assunto em seus arts. 13 a 15. Dispõe o art. 15 do Código Civil: "ninguém pode ser constrangido a submeter-se, com risco de vida, a tratamento médico ou intervenção cirúrgica."

(10) Também podem ser encontradas proteções à integridade física e mental dos cidadãos nos códigos de ética dos demais profissionais de sáude, como o Código de Ética Farmacêutica (Resolução CFF n. 417/2004, art. 13); o Código de Ética Odontológica (Resolução CFO n. 42/2003); assim como o Código de Ética do Psicólogo (Resolução CFP n. 010/05). 


\section{III - O PRINCÍPIO CONSTITUCIONAL DA LIBERDADE E SUA APLICAÇÃO AOS MÉDICOS E PACIENTES}

A liberdade é um princípio fundamental que rege os serviços de saúde. Decerto que ela poderá ser limitada sempre que houver motivos de interesse público que assim exijam em benefício da coletividade. O princípio da liberdade no Direito Sanitário assume, assim, características específicas que merecem atenção mais detalhada. Na discussão sobre a eutanásia, devese considerar, de um lado, a liberdade de exercício profissional e, de outro lado, a dos pacientes de escolha do médico e do tratamento a ser seguido.

\section{A - O Princípio da liberdade e os usuários de serviços de saúde}

O direito à liberdade com relação aos usuários das ações e serviços de saúde abrange a escolha do médico e a do tratamento a ser seguido. Essa possibilidade decorre do princípio da liberdade, segundo o qual nenhum usuário de serviço de saúde pode ser obrigado a ser atendido por um médico específico sem o seu consentimento, o qual encontra-se expressamente previsto no Código de Ética Médica, que prevê em seu art. 46: "É vedado ao médico efetuar qualquer procedimento médico sem o esclarecimento e consentimento prévios do paciente ou de seu responsável legal, salvo iminente perigo de vida".

Para que esse princípio seja aplicado de forma integral, o Código de Etica Médica proíbe ao médico, em seu art. $9^{\circ}$, fazer propagandas, publicidades ou quaisquer tipos de ações que assemelhem a prática da Medicina a uma prática comercial: "A Medicina não pode, em qualquer circunstância, ou de qualquer forma, ser exercida como comércio". Essa interdição é feita a fim de evitar que o usuário de serviços de saúde seja induzido à escolha de um profissional em decorrência de publicidade feita em meios de comunicação de massa, através de mecanismos de convencimento que pouco instruem sobre a qualificação do médico.

O usuário dos serviços de saúde tem, também, total liberdade de escolha dos procedimentos terapêuticos que deverá seguir para a recuperação de sua saúde (se e quando possível). O Código de Ética Médica proíbe o médico de exercer sua autoridade de maneira a limitar o direito do paciente de decidir livremente sobre a sua pessoa ou seu bem-estar, aí incluida a opção de tratamento a ser seguido (art. 48). No mesmo sentido, é vedado ao médico desrespeitar o direito do paciente de decidir livremente sobre a execução de práticas diagnósticas ou terapêuticas, salvo em caso de iminente perigo de vida (art. 56) ${ }^{(11)}$ que possa ser solucionado com intervenção médica.

(11) Disposições no sentido de que o profissional de saúde deve respeitar o direito do paciente de decidir, dentro das possibilidades terapêuticas possiveis, sobre o tratamento a que se submeterá 
Conclui-se, portanto, que o paciente terminal tem o direito de escolher uma morte digna, recusando-se a seguir procedimentos e tratamentos médicos que não salvarão a sua vida, mas apenas prolongarão o seu sofrimento. Esta escolha é do indivíduo, subjetiva, e o médico deve auxiliar ao máximo para preservar o interesse do paciente e adotar os cuidados necessários para aliviar os sintomas que levam ao sofrimento, assegurandoIhe conforto físico, psíquico, social e espiritual, assegurando-Ihe, enfim, uma morte digna.

\section{B-A liberdade do médico}

O princípio da liberdade é válido para os médicos a fim de que possam desenvolver o bom exercício de suas funções. A liberdade do médico pode ser traduzida pela liberdade de exercício profissional, condicionada ao devido registro no Conselho de Medicina, de escolha dos seus pacientes, instalação e de prescrição. Esses princípios se aplicam - em geral e salvo quaisquer adaptações relacionadas ao tipo de especialidade - a todos os profissionais de saúde (psicólogos, psiquiatras, enfermeiros, dentistas, assistentes de saúde etc.). Interessa neste artigo, sobretudo, analisar a liberdade de prescrição do médico, uma vez que a Resolução $n$. 1.805/06 trata de "limitar ou suspender procedimentos e tratamentos", atos intrínsecos à prescrição médica.

A liberdade de prescrição do médico é uma conseqüência da sua autonomia no exercício profissional. Compete ao médico, a partir de seu diagnóstico, decidir sobre o tratamento a ser sugerido ao paciente, bem como os medicamentos e procedimentos que eventualmente deverão ser adotados, tais como exames clínicos, internação, cirurgias etc. É nesse sentido que $o$ art. 21 do CEM garante ao médico o direito de indicar o procedimento adequado ao paciente, observadas as práticas reconhecidamente aceitas e respeitando as normas legais vigentes no País.

Assim, a liberdade de prescrição do médico está condicionada ao bom diagnóstico e ao respeito às práticas reconhecidamente aceitas e às normas legais. No que se refere ao bom diagnóstico, 0 art. 27 do CEM exige que 0 médico dedique ao paciente, quando trabalhar com relação de emprego, o tempo que sua experiência e capacidade profissional recomendarem para o desempenho de sua atividade, evitando que o acúmulo de encargos ou de consultas prejudique o paciente.

Com relação ao tratamento prescrito, o médico deve praticar ou indicar atos médicos que se mostrarem necessários e que forem admitidos

são encontradas em todos os Códigos de Ética de profissionais de saúde, como o dos psicólogos, enfermeiros, farmacêuticos e dentistas. 
na legislação brasileira, em especial no que se refere a transplantes de órgãos ou tecidos ou de partes do corpo humano, a práticas de esterilização, fecundação artificial ou abortamento. O médico não está vinculado aos protocolos terapêuticos estabelecidos pelos órgãos competentes, mas assume o risco caso prescreva tratamentos alternativos aos usualmente adotados. Nesses casos, ele tem a obrigação de informar ao paciente sobre a sua opção, esclarecendo sobre a possibilidade de adotar os procedimentos sugeridos pelos protocolos terapêuticos.

O exercicio da liberdade de prescrição pelo médico deve ser feito com parcimônia. Sempre deverão ser consideradas as condições peculiares do paciente e a eficácia do tratamento possivel de ser aplicado. Nesse sentido, e no que se refere à Resolução do CFM, parece natural que o médico possa adotar a eutanásia passiva em uma situação onde o paciente encontra-se em fase terminal, sofrendo e sem possibilidade de cura, situação na qual os protocolos terapêuticos apenas servirão para prolongar o sofrimento do paciente. Entre o prolongamento do sofrimento de um paciente sem cura e terminal e a sua condução suave para uma morte digna e indolor, a opção adotada pelo CFM, de limitar ou suspender o tratamento com o consentimento do paciente ou de seu representante legal, mostra-se a mais humana.

\section{IV - O DIREITO DE MORRER DIGNAMENTE}

Um aspecto que vem sendo discutido cada vez mais fortemente e que está diretamente relacionado com o princípio da proteção da dignidade humana é o direito de morrer dignamente. Trata-se de uma reivindicação cada vez mais corrente na sociedade. Na França, por exemplo, a Association Pour le Droit de Mourir dans la dignité - ADMD (Associação pelo Direito de Morrer Dignamente) reúne mais de 30 mil aderentes e é coordenada por um senador francês, Sr. Caillavet, membro do Comitê Nacional de Ética.

No Brasil, além da recém-aprovada Resolução ora em análise, vale mencionar o brilhante livro publicado pelo médico Dráusio Varella, "Por um Fio" (12), no qual relata, com notável sensibilidade, como alguns doentes terminais desejariam acelerar os seus últimos momentos de agonia.

$\mathrm{O}$ argumento levantado pelos defensores da morte digna é que, nos casos dos doentes terminais, muitas vezes a compulsoriedade do tratamento, ou a execução de protocolos terapêuticos inúteis que têm por objetivo prorrogar a vida do paciente por mais um ou dois meses, representam verdadeiros atentados à dignidade humana. O sofrimento físico e moral vivido

(12) VARELLA, Dráusio. Por um Fio. Cia das Letras. 
pelo doente terminal (ou vegetal) adquire uma importância jurídica na medida em que ele pode significar um atentado à dignidade humana. Muitos preferem morrer dignamente a ter que se submeter a tratamentos dolorosos e sem eficácia (ou pior, como no caso da norte americana Terry Schiavo, que viveu mais de 20 anos de maneira vegetal, sem possibilidade de cura).

Atualmente, no Brasil, a eutanásia ativa é tratada como homicídio. Tramita no Senado Federal o Projeto de Lei n. 125/96, que visa estabelecer critérios para a legalização da morte sem dor. O projeto prevê a possibilidade de que pessoas com sofrimento físico ou psíquico possam solicitar que sejam realizados procedimentos que visem sua própria morte. A autorização para estes procedimentos será dada por uma junta médica, composta por cinco membros, sendo dois especialistas na doença que acomete o solicitante. Caso este esteja impossibilitado de expressar sua vontade, tal desejo poderia ser expresso por um familiar ou pessoa próxima. Também há no Congresso Nacional um Anteprojeto de Lei propondo a alteração do art. 121 do Código Penal, inserindo um tratamento específico para a eutanásia ${ }^{(13)}$.

O Código de Ética Médica proibe expressamente a prática da eutanásia ativa ou indireta em seu art. 66, dispondo ser vedado ao médico "utilizar, em qualquer caso, meios destinados a abreviar a vida do paciente, ainda que a pedido deste ou de seu responsável legal". Fica assim evidente, portanto, que a abrangência da Resolução do CFM limita-se à eutanásia passiva, ou seja, limita-se a possibilitar ao médico limitar ou suspender um tratamento que, ao final, demonstra-se desumano e degradante, servindo apenas para preservar uma vida que, em fase terminal, não preserva a dignidade do seu titular.

A França viveu um debate intenso sobre o assunto, que culminou na aprovação de uma Lei de 2005 que autoriza o que se convencionou chamar de "eutanásia passiva", ou seja, autoriza o médico a deixar de empregar tratamentos inúteis para uma tentativa de cura impossível, bem como a empregar todos os meios possíveis para reduzir a dor do doente que está prestes a morrer, mesmo que esses meios reduzam o tempo de vida do doente (por exemplo, aplicações regulares de doses de morfina para reduzir a dor) ${ }^{(14)}$.

(13) Sugere o Anteprojeto o seguinte texto: " $\S 3^{\circ}$ Eutanásia: se o autor do crime agiu por compaixão, a pedido da vítima, imputável e maior, para abreviar-lhe o sofrimento físico insuportável, em razão de doença grave: Pena - reclusão de três a seis anos" (contra seis a 20 do homicídio simples). $\S 4^{\circ}$ Exclusão de ilicitude: Não constitui crime deixar de manter a vida de alguém por meio artificial, se previamente atestada por dois médicos, a morte como iminente e inevitável, e desde que haja consentimento do paciente, ou na sua impossibilidade, do ascendente, descendente, cônjuge, companheiro ou irmão.

(14) "Em 2002, o então ministro da saúde da França, Dr. Kouchner, expressou a seguinte opinião sobre o assunto: "A questão do fim da vida, mesmo que difícil, deve ser colocada e debatida. Seria um grande erro tentar ocultar um problema que concerne a cada cidadão e que corresponde a uma realidade tão universal quanto inevitável. Uma sociedade democrática deve se interrogar sobre a maneira como ela cuida de suas doenças, das deficiências e da morte. É primordial tomar o tempo 
Esse debate prosseguiu na França e os direitos dos doentes têm recebido do Direito Sanitário francês uma proteção cada vez mais forte. Uma lei de 22 de abril de 2005 criou a possibilidade do médico se recusar a empregar tratamentos dolorosos, não razoáveis e que nitidamente não resultarão na cura do paciente. Dispõe a lei que "toda pessoa tem, conforme o seu estado de saúde e a urgência das intervenções médicas que são necessárias, o direito de receber os cuidados mais apropriados e de se beneficiar de tratamentos terapêuticos cuja eficácia e segurança sanitárias sejam garantidas pelos protocolos médicos existentes. Os atos de prevenção, investigação ou de cuidados não devem, no estado de conhecimentos médicos existentes, fazer o doente correr riscos desproporcionais aos benefícios possiveis. Esses atos não podem ser perseguidos com uma obstinação desarrazoada. Sempre que tais atos se mostrarem inúteis, desproporcionais ou sem outro efeito além de manter a vida artificialmente, eles poderão ser suspensos ou não serem mais executados".

\section{A - Necessidade de maior discussão no Brasil sobre o tema}

Embora Constitucional, por proteger a dignidade humana e a liberdade dos pacientes e dos médicos, a Resolução do CFM não encerra os problemas que cercam o tema da eutanásia. Viu-se que a posição brasileira, nesse sentido, parece ainda estar resumida no art. 66 do Código de Ética Médica, agora amenizado por esta Resolução. À luz da dignidade da pessoa humana, inclusive da pessoa em fim de vida, o assunto referente à eutanásia (passiva, ativa ou indireta) merece discussão mais aprofundada no Brasil, bem como um tratamento mais adequado da legislação. A sociedade brasileira não pode furtar-se de enfrentar essa questão que é fundamental para o pleno respeito à dignidade humana, principalmente aquela do doente em fim de vida.

que for necessário para debater todas as questões relacionadas ao fim da vida. Acompanhar a pessoa que está morrendo até os seus últimos momentos, diminuir os seus sofrimentos, assegurar uma qualidade de vida digna, proteger a dignidade do doente e oferecer conforto para seus familiares são principios que inspiram a lei de 1999 que visa garantir o acesso de todos aos cuidados paliativos. Alguns progressos foram trazidos para as pessoas que estão à beira da morte, mas novos progressos devem ser buscados. Algumas questões particularmente dolorosas relacionadas com o fim da vida ainda estão sem resposta. Somos obrigados a constatar que certas situações escapam dos meros cuidados paliativos. É o caso notadamente da pessoa consciente, capaz de exprimir nítida e livremente a sua vontade e que reivindica uma 'assistência à morte consentida', segundo os termos utilizados pelo Comitê Nacional Consultativo de Ética, para colocar um fim aos seus sofrimentos físicos e mentais. As respostas aplicadas por alguns de nossos vizinhos Europeus oferecem pistas de reflexão sobre o assunto. Mas também temos as situações onde as pessoas doentes não são capazes de exprimir qualquer vontade. Essas situações ainda restam sem respostas. Uma resposta única que não seja capaz de dar conta da multiplicidade de situações e de individuos deve ser rejeitada. No entanto, nós não podemos aceitar que se perpetuem as práticas individuais, solidárias e clandestinas. É necessário aprofundar a reflexão sobre quais as condições que poderiam melhor assegurar o respeito à autonomia e à dignidade da pessoa doente, principio fundamental do projeto de lei relativo aos direitos dos doentes e à qualidade do sistema de sáude da frança". JO Sénat, Q. N. 2, 10 de janeiro de 2002, p. 99. 
Certamente que uma Resolução do CFM, pela sua escala hierárquica no Direito Brasileiro, não tem o condão de definir a posição da sociedade sobre o fim da vida. Tal Resolução somente irá acalentar os médicos que já praticam esse tipo de procedimento, mesmo sem respaldo mais sólido da Lei. Trata-se de um procedimento de humanidade, de compaixão humanista, que pode ser compreendido como um crime em decorrência de um tratamento inadequado dado pela Legislação Federal atualmente.

Somente uma Lei aprovada pelo Congresso Nacional irá solucionar o dilema. O Direito deve evoluir para acompanhar as transformações da sociedade e prever, finalmente, como e quando pode-se praticar a eutanásia no Brasil. A Resolução do CFM não aborda questões importantes sobre o tema da eutanásia, especialmente no que diz respeito aos procedimentos necessários para evitar abusos por parte dos médicos. Nesse sentido, a legislação federal deverá prever, entre outros aspectos: a) a eutanásia é admitida no Brasil? b) Em que condições? c) Como formalizar o consentimento do paciente? d) Quem é o representante legal apto a dar o consentimento no lugar do paciente incapaz?

Vê-se, assim, que embora a Resolução do CFM represente um importante avanço na regulação da eutanásia no Pais, e esteja de acordo com os principios constitucionais da dignidade humana e da liberdade, somente uma Lei Federal poderá resolver definitivamente se a eutanásia é ou não é crime no Brasil. 